\title{
Preparing the stage for using emerging technologies in science education
}

\author{
Dr Christine Redman \\ The University of Melbourne, Graduate School of Education, Melbourne, \\ 3010, Victoria, Australia, redmanc@unimelb.edu.au \\ http://www.edfac.unimelb.edu.au/sme/about/redman.html
}

\begin{abstract}
This paper reviews a sequence of learning experiences that were embedded into a university subject that sought, in part, to support the purposeful uptake of 'emerging technologies'. The assumption that university students use technology regularly does not take account that only certain types of technologies are utilized, and more for immediate social purposes. This paper explains how and why different technologies were selected for use in a university subject. The decisions were informed by a sound pedagogical approach designed to deepen the teaching and learning experiences with the science concepts. The technologies were potentially those that could contribute to more effective classroom teaching of science education. Enriching dialogical and social learning communities formed progressively during student participation with, and use of a range of technologies and engagement with science conceptual challenges. These communities had sharply focused and targeted science learning outcomes, yet used a creative and discursive centered approach for extending and sharing their new and refined understandings.
\end{abstract}

\section{Background to the Study}

This paper describes an approach to staging the learning experiences in science education using a pedagogical informed approach that inculcated technology tools in a university level subject. The approach was, in part, designed as a response to a preliminary 2006 report conducted by research teams from the Biomedical Multimedia unit and the Centre for the Study of Higher Education at The University of Melbourne [1]. The Melbourne University study (MUS) reported that first-year students were regular users of a variety of technologies, and indicated students used 'emerging technologies' but not in the ways expected. In this study 'emerging technologies' refers to blogging and video-podcasting. They were chosen as they were the less familiar technologies, and yet had sound pedagogical potential for 
classrooms. A 2007 Curtin University study found 'few students (7.3\%) were frequent users of blogs' [2] and subsequently recommended that 'university teacher(s) ... challenge them (students) to go beyond their use purely for social ends, and use them to be participative constructors of knowledge in engaging learning experiences'[2]. The two University studies identified blogging and videopodcasting, as learning experiences provided for a 4-year, pre-service primary teacher degree subject.

The science learning experiences incorporated pedagogically useful tools for personal learning, and these were embedded into the sequential science informed way of immersing these emerging technologies into a pre-service teacher (PST) subject. The sequencing and use of the technologies emanated from a socialconstructivist learning theory approach [3], which informed the choice of pedagogical strategies. These strategies aimed to provide PSTs with insights into more effective approaches for using Information Communication Technology (ICT) for enhancing learning opportunities while enhancing their own science teaching and learning experiences.

The MUS had sought to understand what being a 2006 Digital Native meant and had reviewed which ICT tools first-year students had used in the previous 12 months. Two thousand first-year students were surveyed and it was found they had unrestricted access to a mobile phone (96\%), desktop computer $(90 \%)$, digital camera (76\%), MP3 player (69\%), lap top computer $(63 \%)$. The most common uses were; sending or receiving email (94\%), creating documents (88\%), playing digital music files (84\%), searching for information (83\%), communicating via instant messaging (80\%). The MUS indicated that certain technology tools were more frequently utilised. Two ICT tools frequently used were the social communication tools of emailing and short messaging service (SMS). Both support instant sharing of ideas while still allowing opportunity for the careful crafting of a written message.

\subsection{Introduction to the Study}

This paper examines the result of a creating a learning journey and how that meta-cognitive approach used a sequence of ICT tools to create rich dialogical learning opportunities. Blogging and video-podcasting were selected as they could utilise and refine their literacy skills of speaking, listening, reading and writing, provide opportunities to re-visit and share their science learning experiences, support reviews of and reflecting on their science experiences and encourage progressively more informed discussions about the science concepts.

Blogging and video-podcasting were incorporated to enhance the meaningful and empowered use of ICT, for quality learning outcomes in science education. The sequence sought to promote the effective development of an understanding about key events in lunar phases. The tools that were used early in the sequence were chosen as they were already part of PST's daily-lived experiences. Emailing and SMS were their more familiar communication devices in their social world [4]. Blogging and video-podcasting were introduced later as the less familiar tools. In the initial survey only 6 out of the 148 PSTs had accessed Podcasts. The use of more familiar 
technologies engendered feelings of confidence as all PST's had mobile phones, and only 10 did not have a built in camera phone.

148 third-year students in the Faculty of Education in a large Australian University were enrolled in this year-long science and technology subject. Prior to this study they had participated in a semester-long ICT-in-Education subject that provided ICT experiences suitable for the primary classroom. The PST's reflected on how their use of ICT tools to enhance and disseminate their science ideas.

In small groups, PST's communicated initially via email and SMS. These ICT tools supported the development of a shared focus in a community of practice, which could later transform into a community of inquiry, [5] as understandings of the science concept developed. The tasks became progressively more technically challenging, as the PST's collaborated to resolve technical difficulties, and they shared their science discoveries in their 'virtual' community of inquiry [6]. The emphasis was not on mastering the technology but rather on working co-operatively to refine and deepen their understanding of a challenging science understanding [7] through engagement with the 'social technology' tools. The imperative of their known needs created a need to turn to others and they found others were resources to help them develop their technological practices and science understandings. This process encouraged their active reflection on their personal learning about the science concepts and importantly ways to utilize ICT to make these science ideas more explicit and available to share [8]. As the PSTs advanced in their science understandings, the ICT tools changed to support their development, sharing, investigation and communication of their science reasoning.

\subsection{Literature Review}

The MUS showed that first-year students in higher education settings had regular Internet access and as 'Digital Natives' accessed a changing range of ICT tools. The term Digital Natives captures the sense of being born into a community, and as the first born growing up with technological practices as 'habits of mind'. They have developed approaches to deal with new ICT tools through their prior practices. Bourdieu called this habitus [9]. Prensky [10] states that Digital Natives have 'spent their entire lives surrounded by and using computers, using video games, digital music players, video cams, cell phones, and all the other toys and tools of the digital age' ( $p$ 1). Yet this use of ICT can be closely tied to personal needs and this can impact on their confidence to try new things, or not [11]. ICT may afford [12] people different opportunities based on their prior experiences and needs. Using ICT to enhance your educational opportunity was provided through discussion, sharing and deepening of understandings. This study sought to see if conversational and social opportunities to reflect on learning could be increased and deepened by including use of the 'social technologies' into the courses.

In this study the integral tasks drew first on the everyday technologies of the mobile phone and email. As the PSTs experienced something new they could instantly share it, using SMS or email. This capitalised on the properties of familiar technology, supporting immediate connection to others, and shared the moment and excitement of learning. Dewey [13] states that learning is part of the social lived 
world and he considered learning experiences to be dynamic. The social elements of ICT support contact at anytime and the immediate sharing of new revelations.

\section{Staging the Learning Experience}

\subsection{Creating and establishing a learning environment that valued learning}

Early in the year the PSTs participated in activities designed to enhance their science knowledge base. The activities sought to extend their understanding of everyday science topics and required them to highlight their new understandings. The PSTs articulated their understandings in twice weekly written responses.

Several activities modeled to PSTs that the development and refinement of knowledge was valued. They were encouraged to enjoy learning new things, to become aware of what it is like to be a learner and to experience curiosity, wonder and discovery. This subject flagged that they did not know 'everything', but that they were actively engaged in an effective learning process and that it was more important to discover 'what they did not know' and to find ways to better understand it.

\subsection{Reflection and Review of one's personal existing understandings}

At the beginning of lectures PSTs probed and recorded their current understandings of science concepts. This exploration of prior knowledge [14] supports learners to examine their current understandings and to explore, probe and test these understanding. Learners are not use to articulating their science understandings, and therefore, may not have the words 'ready at hand' to express what their thoughts. So, when pressed to explain a science concept, they can not always explain it, nor are they able to state all that they know. While discussing their tentative explanations, PST'S state 'oh, yes and...' as they recollect connected ideas.

In lectures, after pondering their understanding, PSTs were sometimes asked to draw their explanation. When labeling their drawing PSTs realised their explanation may not be correct and how well they understand it, and become aware of what need to know to be able to explain it. 'I am curious about the angle to which the moon changes shape .... Sorry if i'm not making any sense, i'm finding it hard to verbalise!' PSTs need to comprehensively understand and be able to articulate science concepts to explain them in classrooms and also to become aware that 'others' may have alternative understandings for many science concepts.

Lunar phases are widely recognised as a conceptually challenging [15-17] and were selected to represent and model aspects of what makes science education difficult to teach [16]. People may have alternative understandings to, or lack awareness of, the scientifically accurate explanation. The PSTs were engaged in understanding a science concept acknowledged to be difficult to reconcile, taking active responsibility for their learning in a progressively meta-cognitive way.

People may hold alternative conceptions such as, 'the earth's shadow causes the moon's shape to change', and are frustrated when they find out this is incorrect. A PST recorded in a lecture, 'I'm not really sure ... We did learn this (before) but I was a little confused then 2'. Another asked, 'Where does the new moon go??' Another 
stated, 'I can't specifically remember how the moon looks at each position, but I have an idea of how it works?'

Once PSTs are aware what they do not specifically understand or can not articulate, they are more likely to want to resolve it. A PST recorded in a lecture that, if the earth is a spherical shape ... why does its shadow cause a concave shape? This is most puzzling for me. I will aim to find the answer to this over the next few weeks of classes.' The second component of this process required the PSTs to explain in words their current understanding of lunar phases, draw their explanation and label their drawing to elucidate and explore their understandings of key events.

Some PSTs became aware that their written explanation did not make sense when transferred into a labeled drawing, but this had highlighted their specific learning needs. It had served to focus them on refining their understanding, language or ability to communicate the ideas. When drawing another PST stated, 'I am not completely sure, but I think it involves the moon rotating on it's axis...'

The PSTs had explored their understanding of lunar phases privately, and perhaps socially and publicly, with friends after the lecture. After these exploratory activities they were aware of their current understandings.

\subsection{Introducing and incorporating Blogging as a learning event}

Blogging provides an effective communication tool for classroom use. Literacy is highly valued in the primary classroom and in science education for communication, reviewing and sharing of ideas. The blogging experience capitalized on the PST's propensity to communicate using email and SMS, and informal language, in their social forms of communication, and may have supported the development and active engagement in the 'virtual conversations'. Blogging was an assessable component of their subject to concede that there was a significant amount of time required and to ensure that all group members participated. The assessment was individually graded and the assessment rubric preferenced the individual's experience, with a component that attended to their shared group journey.

Guidelines for the blogging discussions encouraged curiosity and an open-ended problem-solving approach. The blogging groups were provided with this focus to sustain their conversations. Over the weeks, it guided them through different ways of engaging with the moon. The blog site was available in the first ten weeks but could be accessed all year. After the year ended PSTs were still posting, and reflecting on what and how they had learnt. 'This blogging experience has unquestionably refined my understandings of the moon and its relationship with the sun and the earth. By beginning with observing the moon it gave me a chance to approach science in a completely different light... The process allowed me to let my guard down, ....

In lectures, aspects of blogging were examined, focusing on how it could contribute to classroom learning. It was concluded that blogs supported the active sharing of ideas and the asking of questions. Drawings and pictures could be scanned in and they could share sound files with each other. Many searched the Internet while blogging, as they attempted to resolve questions, and shared websites. 'Hey I was so into this website it has so muich (sic) information on everything that you would need to know as a teacher and it is fantastic!!! The site is run by..." And another, 'hey guys, here is a calendar showing phases of the moon this year, just thought it was 
interesting to see if our observations were accurate. (I hope $i$ can upload it properly!) The response was ... Yes you did upload the moon calendar correctly! Thanks so much for that! It was really interesting ....

The formal assessment of the blog took account of the PST's personal learning and growth in science knowledge and the development of their professional awareness of blogging as a tool for teaching and learning in the classroom. 'hahahaha I see what you are saying but I think that the moon would continue to orbit the way it but then again hypothetically what if the earth ... i don't know $i$ think $i$ am confusing myself'

\subsection{Sharing the learning experience through Video-podcasting}

PSTs were introduced to four Podcasts, three were science focused and came from the United Kingdom, United States and Australian universities. They presented recent science research and interviews with scientists, adding a richer human account to the research journey. The fourth podcast focused on a father and his eight-year-old son talking about their daily lives. PSTs enjoyed this podcast immensely.

PSTs created a video-podcast that shared their group's deliberations on blogging as a tool explaining how it had supported their learning about lunar phases. They included their lunar photos, drawings and photos of their dynamic lunar models and they demonstrated the ideas they needed to understand lunar phases, based on their experiences as learners and teachers, 'I feel like the podcast process has really extended my understandings. At the end of the first assignment, I was only in tune with the ideas and concepts that I had just discovered, and the implications for learning based on my experiences as a learner. ... I now feel like I have a deeper level of understanding.' From another PST 'So I am looking at how our blogging ... has helped my understandings. When I look back at my original drawings I can see that I wasn't very aware of where the light was in my pictures... This was a really important part in my learning journey and where I really started to make connections and answer my own questions.'

\section{Behind the scenes -}

\subsection{Weaknesses/Difficulties}

It took many meetings in the previous year to set up blogging. Choices included:

1. run it in a university site or in an Education Faculty site

2. have it open to the world, or only to the blogging group

3. software packages that were free or need to be purchased

4. with or without images and sound files

A team took time to create the structure to work with multiple blog groups. This took more time than anticipated, but was stable. Getting groups formed was timeconsuming. Students could not always log in, or post a blog or lost their passwords. Some groups commented regularly on each other's posts and uploaded images. Some groups had 'lurkers' who took awhile to get involved. Many PSTs learnt new skills and celebrated, 'sorry about the ... $i$ have had to combat all sorts of technological 
difficulties to post our photos from our modelling session. but $i$ have finally conquered all my technological demons, triumph is mine! here they are so enjoy...'

\subsection{Strengths/Successes}

The technical advice and support was terrific. Without this structure the project would never have happened. Students gave technical assistance to others and shared their hints with groups. Late in 2008 interviews will be conducted to ascertain the stability of their science understandings and their reflections on the use of blogging and video-podcasting. Initial forays indicate that the experience was positive.

\section{Conclusion}

The ICT tools appeared to be 'a natural' fit into the PSTs' lifestyle. Emailing and SMS were successful. Blogging seems to have been effective, perhaps as it was relatively easy, quick to do and supported their sense as primary teachers who prioritize development of student's literacy skills. Video podcasting created an audience, a reason to reflect on, communicate and celebrate their achievements. The sharing of their lived experiences was felt to be enhanced due to the deliberate slow staging and establishing of a virtual learning community who felt comfortable exploring and developing their science understandings together. It appears that they have transformed their understandings through shared and lived experiences rather than reproducing knowledge from books [18]. In the scaffolding of their experiences and sense of a shared purpose in a virtual community of inquiry, they were focused on a joint project [6] and a desire to better understand lunar phases. The ICT tools appeared to have served them well. It supported them as they developed new practices and ways to interact with and make sense of the material world $[4,9,20]$.

\section{References}

1. G. Kennedy, K.-L. Krause, T. Judd, A. Churchward, and K. Gray, First year students' experiences with technology: Are they really digital natives? Melbourne, Australia: Biomedical Multimedia Unit, University of Melbourne. [November 9, 2007] http://www.bmu.unimelb.edu.au/research/munatives/natives_ report2006.pdf

2. B. Oliver, and V. Goerke, Australian undergraduates' use and ownership of emerging technologies; Implications and opportunities for creating engaging learning experiences for the Net Generation, Australasian Journal of Educational Technology. 23(2), 171-186 (2007).

3. K. R. Skamp, Teaching primary science constructively (Thomson Learning, Melbourne, 2007).

4. R. Harré, Material objects in social worlds, Theory, Culture \& Society. 19 (5-6), 23-33 (2002). 
5. J.B. Pena-Shaff and C. Nicholls, Analyzing student interactions and meaning construction in computer bulletin board discussions, Computers \& Education. 42(3), 243-265 (2004).

6. T. Schatzki, Social Practices: A Wittgensteinian approach to human activity and the social (Cambridge University Press, Cambridge, 1996).

7. C. Redman and R. Fawns, Discursive positioning and effecting change in a community of practice. (2004) (November 9, 2007); www.aare.edu.au/04pap/ red04632.pdf

8. J. Dewey, Experience and nature (Dover Publications, New York, 1925).

9. P. Bourdieu, Outline of a Theory of Practice (Cambridge University Press, Cambridge, 1977).

10. M. Prensky, Digital Natives, Digital Immigrants, On the horizon. (accessed November 9, 2007); http://www.marcprensky.com/writing/Prensky\%20\%20Digital\%20Natives,\%20Digital\%20Immigrants\%20-\%20Part1.pdf

11. C. Redman, Towards a dialogical perspective on agency in student learning. (2007) (November 9, 2007); http://www.aare.edu.au/07pap/red07364.pdf

12. J. Gibson, The ecological approach to visual perception (Houghton Mifflin, Boston, 1979).

13. J. Dewey, The public and its problems (Ohio University Press, Athens, 1927).

14. R. Driver, H. Asoko, J. Leach, E. Mortimer, and P. Scott, Constructing scientific knowledge in the classroom, Educational Researcher. 23(7), 5-12 (1994).

15. V. A. Atwood and R.K. Atwood, Preservice elementary teachers' conceptions of what causes day and night, School Science and Mathematics 95, 290-294 (1995).

16. C. Redman, Moon rise, Moon set, Investigating 1(17), 22-7 (2001).

17. K. C. Trundle, R.K. Atwood, and J.E. Christopher, Preservice elementary teachers' conceptions of moon phases before and after instruction, Journal of Research in Science Teaching 39(7), 633-658 (2002).

18. R.A. Bhaskar, Reflections On Meta-Reality: A Philosophy for the Present (Sage, New Delhi, 2002).

19. C. Linehan and J. McCarthy, Positioning in practice: Understanding participation in the social world, Journal for the Theory of Social Behaviour, 30, 435-453 (2000).

20. P. Sullivan and J. McCarthy, Toward a dialogical perspective on agency, Journal for the Theory of Social Behaviour, 34, 291-309 (2004). 